\title{
Development of tolerance to ethanol in relation to the alcohol dehydrogenase locus in Drosophila melanogaster 1. Adult and egg-to-adult survival in relation to $\mathrm{ADH}$ activity
}

\author{
J. W. M. Kerver and \\ W. van Delden
}

Department of Genetics, University of Groningen, Kerklaan 30, 9751 NN Haren, The Netherlands.

Strains of Drosophila melanogaster homoxygous either for the $A d h^{F}$ or the $A d h^{S}$ allele, were kept on food supplemented with ethanol. After 90 generations these strains (FFE and SSE) were tested for tolerance to ethanol and compared with control strains (FFN and SSN) from regular food. The E strains showed increased tolerance to ethanol, both in the adult and in the juvenile life stages. In the adults the increase in tolerance was not accompanied by an increase in $\mathrm{ADH}$ activity. In the juvenile life stages there were significant differences in $\mathrm{ADH}$ activity between the $\mathrm{E}$ and $\mathbf{N}$ strains, both on regular food and on food containing ethanol. However, ADH activity was not the only factor involved in the increased tolerance to ethanol.

The $A d h$ genotype of the mother was of paramount importance to egg-to-adult survival because of a maternal effect on ethanol tolerance in the eggs and first instar larvae. Furthermore developmental times of the $E$ strains were longer than those of the corresponding $\mathbf{N}$ strains. It is concluded that the adaptation to ethanol-containing food was not realised in the same way in the FFE and SSE strains.

\section{INTRODUCTION}

Surveys of enzyme polymorphisms for a wide range of animal and plant species show that most species are highly polymorphic (see reviews by Powell, 1975; Nevo, 1978 and Hamrick et al., 1979). Two alternative hypotheses have been proposed for the maintenance of this kind of genetic variation, giving rise to a dispute now widely known as the neutralist-selectionist controversy (for extensive treatments see Lewontin, 1974, and Kimura, 1983). A complication connected with the interpretation of experimental data is, that changes in allele frequencies at a particular enzyme locus may be the result of selection acting on one or more unknown linked loci, in linkage disequilibrium with the locus under study. If it can be demonstrated, however, that reproducible changes in allele frequencies are associated with the presence of the relevant substrate of the enzyme, an argument for the action of selection at that particular allozyme locus is provided (Clarke, 1975). Such a relationship has been demonstrated for the alcohol dehydrogenase $(A d h)$ locus in Drosophila melanogaster (see van Delden, 1982, for a review).

Several authors have reported an increase in frequency of the $A d h^{F}$ allele on food supplemented with ethanol (Gibson, 1970; BijlsmaMeeles and van Delden, 1974; van Delden et al., 1978; Cavener and Clegg, 1978; 1981) or other alcohols (van Delden et al., 1975). Furthermore it has been demonstrated that the differences in in vitro ADH activities between the $A d h$ genotypes positively correlate with survival on alcohol supplemented food (Day et al., 1974a, b; Briscoe et al., 1975; van Delden et al., 1978; van Delden and Kamping, 1983). Some authors have shown that this relationship also holds for strains of the same electrophoretic mobility, but differing in ADH activity (Thompson and Kaiser, 1977; Kamping and van Delden, 1978). However an increase in ethanol tolerance is not invariably 
associated with an increase in $\mathrm{ADH}^{F}$ frequency or with an increase in in vitro ADH activity (Gibson et al., 1979; Oakeshott, 1979; Anderson, 1982; Ziolo and Parsons, 1982).

Differences in allele frequency connected with the presence of ethanol have also been found in some natural populations of $D$. melanogaster. Briscoe et al. (1975) and Hickey and McLean (1980) reported higher $A d h^{F}$ frequencies for Spanish and Canadian winery populations respectively, compared with surrounding populations. McKenzie and McKechnie (1978) on the other hand found no differentiation in allele frequencies between cellar populations and non-cellar populations although tolerance to ethanol in the former populations was considerably higher. This indicates that increased tolerance to ethanol may also depend on other loci than the Adh locus.

As it appears that $A d h$ variants are frequently not neutral on alcohol supplemented media, and as ADH plays an important role in the detoxification of ethanol it is to be expected that, when both $A d h^{S}$ and $A d h^{F}$ strains of D. melanogaster are exposed to longterm selection by environmental ethanol, differences in tolerance to ethanol, if any, will be positively correlated with ADH activities (McKenzie and Parsons, 1974; David et al., 1976; 1978; 1981; van Delden et al., 1978). A higher survival of flies from strains of $D$. melanogaster, selected for adult ethanol tolerance, compared with control flies was found by David and Bocquet (1977) and by McDonald et al. (1977); the latter authors observed that the differences in survival were positively associated with in vitro $\mathrm{ADH}$ activities. Dorado and Barbancho (1984) found comparable results for egg-to-adult survival. Van Delden and Kamping (1983) reported an increase in tolerance to hexanol both in the adult and juvenile life stages for strains kept for many generations on food supplemented with hexanol.

In the present paper the effect of longterm exposure during the whole life cycle to environmental ethanol for the different $A d h$ genotypes of $D$. melanogaster is studied with respect to adult mortality and egg-to-adult survival, both in relation to in vitro ADH activity. It will be demonstrated that the tolerance to ethanol of the selected strains has been increased as compared with the corresponding control strains, both in the adult and juvenile life stages. $\mathrm{ADH}$ activity plays an important role in the process of adaptation, especially during the juvenile life stages but it is not the only factor involved in the increased ethanol tolerance. In this respect maternal effects are of great influence as well.

\section{MATERIALS AND METHODS}

\section{(i) Strains}

Two strains of Drosophila melanogaster, one homozygous for the $A d h^{F}$ allele (FF) and the other homozygous for the $A d h^{S}$ allele (SS) were used. Each strain was composed by intercrossing eight homozygous Groningen-B lines of the appropriate genotype (for details on the Groningen-B lines see van Delden et al., 1978). Both strains were kept continuously on regular food for about 120 generations or, for selection purposes, on food containing ethanol for about 90 generations. The strains kept on regular food will be referred to as FFN and SSN respectively while the strains kept on ethanol supplemented food will be called FFE and SSE.

\section{(ii) Food and culture conditions}

Regular food contained $18 \mathrm{~g}$ agar, $54 \mathrm{~g}$ sucrose, $32 \mathrm{~g}$ dried dead yeast and $13 \mathrm{ml}$ of a nipagin solution ( $10 \mathrm{~g}$ nipagin in $100 \mathrm{ml}$ ethanol 96 per cent) in 1 litre water. Ethanol food was made by adding the appropriate volume of ethanol (96 per cent) to normal medium with vigorous stirring, after the medium had been cooled to $50^{\circ} \mathrm{C}$. For the E strains the ethanol concentration was raised from an initial 12 per cent by volume to 18 per cent in three steps.

Ethanol food was always stored at $4^{\circ} \mathrm{C}$ and used about 24 hours after preparation. Each of the four strains was maintained in 20 bottles $(125 \mathrm{ml})$ containing $30 \mathrm{ml}$ of food. In each generation about 30 pairs of parents per bottle of regular food were allowed to produce eggs for 3 days after which they were discarded; on ethanol food, however, about 70 pairs of parents were kept for 7 days in each culture bottle before they were discarded. This regime resulted in about equal numbers of emerging adults in all strains. After two ( $\mathrm{N}$ strains) or three weeks (E strains) all the emerged flies of a strain were mixed and subsequently distributed over 20 new bottles containing either fresh regular food ( $\mathrm{N}$ strains) or fresh ethanol food ( $\mathrm{E}$ strains). All experiments were performed at $25^{\circ} \mathrm{C}$ and $50-70$ per cent R.H.

\section{(iii) Adult mortality measurements}

After exposure to ethanol for about 90 generations the E strains were compared with the $\mathrm{N}$ strains for tolerance to ethanol. Adult mortality was measured in glass vials ( $80 \mathrm{~mm}$ high, $23 \mathrm{~mm}$ diameter) containing $9 \mathrm{ml}$ of food to which ethanol in a given concentration was added. The following con- 
centrations were used: 0 (controls), 20, 25, 30 and 35 per cent $\mathrm{v} / \mathrm{v}$. To avoid phenotypic effects the flies used were all raised under identical uncrowded conditions on normal food during one generation preceding the adult mortality test. They were collected, sexed and divided into groups of 10 individuals each, under ether anesthesia, on the third day after emergence and set up on regular food. After another three days the flies were transferred to test vials. Thereafter the number of dead flies in the test vials was recorded twice a day for 72 hours. The number of replicates was 10 for each strain, sex and concentration.

\section{(iv) Egg-to-adult survival}

Egg-to-adult survival was measured in glass vials containing $9 \mathrm{ml}$ of food with a given ethanol concentration: 0 (controls), $12,15,18$ or 21 per cent $\mathrm{v} / \mathrm{v}$. Virgin females raised on normal food under uncrowded conditions were collected and crossed with males of the appropriate genotype to obtain eggs of the required genotypes. For the crosses the first symbol always refers to the homozygous $A d h$ genotype of the mother and the second to that of the father, while the third symbol refers to the medium on which the strains had been kept all the time. In case of FSN, for instance, homozygous F females and homozygous $\mathrm{S}$ males, both from the $\mathrm{N}$ strains, were crossed to obtain FS eggs. To stimulate egg production flies were fed with additional live yeast for three days before transferring them to the egg laying vials. These vials $(50 \mathrm{~mm}$ high, $85 \mathrm{~mm}$ diameter) were provided with a lid containing a thin layer of normal food and a little drop of live yeast. Half an hour after transferring the flies to the egg laying vials, the lids were replaced and the flies were allowed to lay eggs during a period of 4 hours. The eggs were washed from the food surface with tap water and collected on a sieve; thereafter they were transferred to black filtering paper, from which they were collected. For all genotypes and concentrations 10 replicates with 50 eggs were tested. The number of emerging flies in each vial was determined twice a day.

\section{(v) Alcohol dehydrogenase activity assays}

To establish the relation between adult survival and in vitro $\mathrm{ADH}$ activity samples of 10 adults (males or females) were taken, weighed and frozen at $-20^{\circ} \mathrm{C}$. Samples were taken at different times during the survival experiment: a) two days before the start of the adult mortality test (4-day-old flies); b) at the start of the test (6-day-old flies); c) part of the surviving flies at the end of the test was used for immediate activity measurement (9-day-old flies surviving on either regular food or food containing ethanol, 25 per cent $\mathrm{v} / \mathrm{v}$ ); d) the other part of the surviving flies was transferred to regular food for 3 more days and $\mathrm{ADH}$ activity was measured thereafter (12-day-old flies).

For measuring ADH activity the samples were either homogenised in $2 \mathrm{ml}$ buffer (FF genotypes) or in $0.5 \mathrm{ml}$ buffer (SS genotypes); the buffer was a $0.05 \mathrm{M}$ tris- $\mathrm{HCl}-0.001 \mathrm{M}$ EDTA buffer of $p \mathrm{H}$ $8 \cdot 5$. Afterwards the homogenates were centrifuged $\left(0^{\circ} \mathrm{C}, 5000 \mathrm{rpm}, 5\right.$ minutes $)$ and $0.10 \mathrm{ml}$ of the supernatant was added to $0.90 \mathrm{ml}$ reaction solution of $0.15 \mathrm{M}$ tris- $\mathrm{HCl}$ buffer, $p \mathrm{H} 8.5$ with a final concentration of $0.2 \mathrm{M}$ isopropanol and $5 \mathrm{mM}$ $\mathrm{NAD}^{+}$. The increase in absorbance at $334 \mathrm{~nm}$ in the reaction mixture was measured in a Vitatron spectrophotometer (light path $1 \mathrm{~cm}, 25^{\circ} \mathrm{C}$ ). For each strain and sampling time five replicates were measured. Enzyme activities were expressed as $\Delta \mathrm{E} \min ^{-1} \cdot \mathrm{mg}$ life weight ${ }^{-1}$.

To study the relation between in vitro $\mathrm{ADH}$ activity and egg-to-adult survival, samples of all $A d h$ genotypes were taken at the following life stages: early eggs (two hours old, referred to as Eggs I), late eggs (18 hours old, Eggs II), late first instar larvae (L I), medium third instar larvae (L III) and late pupae (P). Samples were collected from both regular food and food containing 15 per cent ethanol. A difficulty in this respect was the difference in developmental time on the two kinds of food used. An attempt was made to collect individuals of the same physiological life stage from regular food and ethanol food. Because of the longer developmental time on ethanol food, however, the individuals of a corresponding physiological age differed in absolute age.

Samples of either 50 eggs, 25 first instar larvae, 10 third instar larvae or 10 pupae were homogenised in $2 \mathrm{ml}$ buffer (see earlier description) and then centrifuged (see $\mathrm{ADH}$ activity assays for adults); $0 \cdot 10 \mathrm{ml}$ of the supernatant was used for ADH activity measurements. The amount of protein was determined by the method of Lowry et al. (1951) using bovine serum albumine (BSA) as a standard. For each strain and life stage three replicates were measured; activities were expressed as $\Delta \mathrm{E} \mathrm{min}^{-1} \cdot \mathrm{mg}$ protein ${ }^{-1}$.

\section{RESULTS}

\section{(i) Adult mortality}

Mortality percentages after 72 hours on ethanol supplemented food are given in figs. $1 \mathrm{~A}$ and 


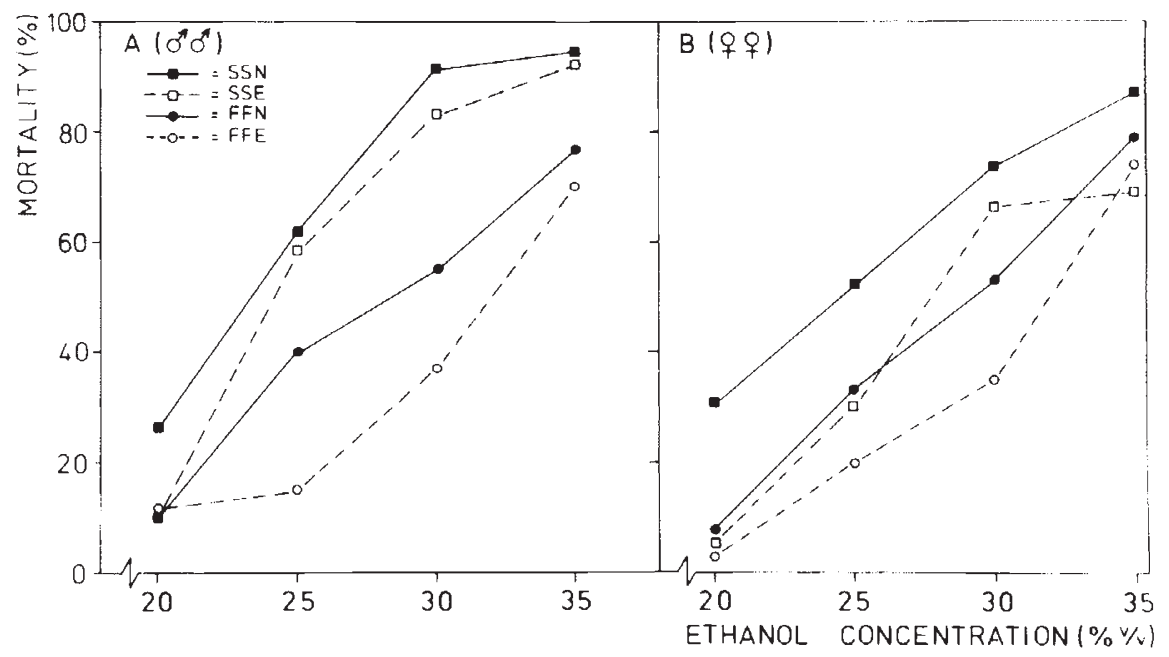

Figure 1 Adult mortality of the control (N) and the selected (E) strains after a stay of 72 hours on food supplemented with different concentrations of ethanol. $A=$ males; $B=$ females.

$1 \mathrm{~B}$; on regular food hardly any flies died. From these figures it is clear, that male mortality on the whole exceeded female mortality. Furthermore it is shown that within each ( $\mathrm{E}$ or $\mathrm{N})$ background the FF genotypes showed a better survival than the SS genotypes. The only exception was found at 35 per cent ethanol where FFE $\$$ ? showed a higher mortality than SSEq9. On the other hand it is also clear that within each genotype the E-flies showed on the average a lower mortality than the $\mathrm{N}$-flies, which were never in contact with ethanol.

Since the relative differences in mortality between the different genotypes were more or less the same for the different ethanol concentrations a three way analysis of variance is only given, as an example, for the mortality on food supplemented with 30 per cent $\mathrm{v} / \mathrm{v}$ ethanol. The results are given in table 1 . From this table it is clear, that the results of the analysis of variance confirm the conclusions from figure 1: a) male mortality was higher than female mortality; b) the mortality of the FF genotype was lower than the SS mortality and c) the E strains showed a lower mortality than the corresponding $\mathrm{N}$ strains.

According to the method of Finney (1947) a probit analysis of adult mortality after 72 hours was performed. The results are given in table 2 ,

Table 2 Median lethal doses $\left(\mathrm{LD}_{50}\right)$ of ethanol expressed as percentages by volume of ethanol in the food, together with their 95 per cent confidence intervals (given in parentheses) for adult survival

\begin{tabular}{lll}
\hline Strain & $\delta \delta$ & $\delta$ \\
\hline SSN & $23 \cdot 3(22 \cdot 7-24 \cdot 0)$ & $24 \cdot 4(23 \cdot 4-25 \cdot 5)$ \\
SSE & $24 \cdot 9(24 \cdot 3-25 \cdot 6)$ & $28 \cdot 6(27 \cdot 6-29 \cdot 6)$ \\
FFN & $28 \cdot 1(27 \cdot 1-29 \cdot 1)$ & $28 \cdot 6(27 \cdot 7-29 \cdot 5)$ \\
FFE & $30 \cdot 7(29 \cdot 4-32 \cdot 1)$ & $29 \cdot 4(28 \cdot 5-30 \cdot 4)$
\end{tabular}

Table 1 Analysis of variance of adult mortality (after angular transformation) after $72 \mathrm{~h}$ of exposure to ethanol supplemented food ( 30 per cent $\mathrm{v} / \mathrm{v}$ )

\begin{tabular}{|c|c|c|c|c|}
\hline Source of variation & $\mathrm{df}$ & Mean square & $\mathrm{F}$ & $\mathrm{P}$ \\
\hline \multicolumn{5}{|l|}{ Adh genotypes (A); } \\
\hline FF vs. SS & 1 & $12726 \cdot 1$ & $57 \cdot 1$ & $<0.001$ \\
\hline \multicolumn{5}{|c|}{ Selection regimes $(\mathrm{B})$} \\
\hline N vs. E & 1 & $956 \cdot 6$ & $4 \cdot 3$ & $0.01<P<0.05$ \\
\hline Sexes (C); $\delta$ vs. $q$ & 1 & $1634 \cdot 2$ & $7 \cdot 3$ & $0.005<P<0.01$ \\
\hline$A \times B$ & 1 & $337 \cdot 8$ & $1 \cdot 5$ & N.S. \\
\hline $\mathrm{A} \times \mathrm{C}$ & 1 & $1266 \cdot 1$ & $5 \cdot 7$ & $0.01<P<0.05$ \\
\hline $\mathrm{B} \times \mathrm{C}$ & 1 & $93 \cdot 2$ & 0.4 & N.S. \\
\hline $\mathrm{A} \times \mathrm{B} \times \mathrm{C}$ & 1 & $117 \cdot 2$ & 0.5 & N.S. \\
\hline Error & 72 & $222 \cdot 7$ & & \\
\hline
\end{tabular}


which shows large differences in median lethal doses $\left(L_{50}\right)$ between some strains, especially for males. The $\mathrm{LD}_{50}$ 's of males differed significantly from each other. For females only the $\mathrm{LD}_{50}$ of the SSN strain differed significantly from those of the three other strains. The average increase of the $\mathrm{LD}_{50}$ of the $\mathrm{E}$ strains compared with the corresponding $\mathrm{N}$ strains was about 10 per cent.

\section{(ii) The relation between adult mortality and in vitro $A D H$ activity}

The results of the ADH activity assays are given in table 3. It is clear that in vitro ADH activities showed an increase with time when the flies were kept continuously on regular food. Furthermore little or no difference was found between activities of flies of the E strains and those of flies of the $\mathrm{N}$ strains of the same electrophoretic class.

An exception was found in the case of the SS females; SSE females had a consistently higher ADH activity on regular food than the SSN females. When transferred to ethanol food, males from the E strains showed no further increase in ADH activity, which was in contrast to the males kept on regular food. This effect was still present when the flies were replaced on normal food again. When transferred to ethanol containing food, males of the $\mathrm{N}$ strains still showed an increase in ADH activity, which was in contrast to the survivors after replacement on normal food. For females the situation was different. The arrest of
ADH activity was only observed in females when they were transferred to regular food.

\section{(iii) Egg-to-adult survival}

As pre-adults are known to be more sensitive to ethanol than adults, it is to be expected that the most severe selection takes place during the preadult life-stage. Therefore the egg-to-adult survival was also studied. The results are shown in figure 2. On regular food about 80 per cent of the eggs reached the adult life stage, except for SFE where viability was only 55-60 per cent. The lower survival of SFE was highly reproducible and will be discussed later on. On food supplemented with ethanol the genotypes of the E strains generally showed a higher survival than the corresponding genotypes of the $\mathrm{N}$ strains, especially at the higher ethanol concentrations. After correction for differences in survival on regular food this was also the case for SFE.

Remarkable in fig. 2 is the striking resemblance between the curves of the $\mathrm{N}$ types with the same mother, SSN and SFN on the one hand compared with FFN and FSN on the other. The curves of the former two genotypes are situated far below the latter two curves. Clearly the $A d h$ genotypes of the mother had an important influence on eggto-adult survival. When survival of SFE on ethanol food was corrected for the survival on regular food the same finding was observed for the E strains, though the difference between the $\mathrm{N}$ strains was

Table 3 Mean in vitro ADH activities, measured in flies of different ages and submitted to different treatments. Activities are expressed as $\Delta \mathrm{E} \cdot 10^{3} \cdot \mathrm{min}^{-1} \cdot \mathrm{mg}$ life weight ${ }^{-1}$; standard errors are given in parentheses. The number of replicates was five

\begin{tabular}{|c|c|c|c|c|c|c|c|}
\hline \multirow[b]{2}{*}{ Sex } & \multirow[b]{2}{*}{ Strain } & \multicolumn{6}{|c|}{ Treatment of flies ${ }^{a}$} \\
\hline & & $4 N$ & $6 \mathrm{~N}$ & $6 N+3 N$ & $6 N+3 E$ & $6 N+3 N+3 N$ & $6 N+3 E+3 N$ \\
\hline & FFE & $109(4 \cdot 1)$ & $133(11 \cdot 4)$ & $133(4 \cdot 3)$ & $136(2 \cdot 8)$ & $189(17 \cdot 4)$ & $130(4 \cdot 6)$ \\
\hline & SSN & $22(0.9)$ & $26(0.9)$ & $30(2 \cdot 8)$ & $34(1 \cdot 4)$ & $45(0.8)$ & $35(0.9)$ \\
\hline & SSE & $25(1 \cdot 1)$ & $32(0.5)$ & $36(2 \cdot 0)$ & $37(2 \cdot 3)$ & $52(3.9)$ & $37(3 \cdot 3)$ \\
\hline \multirow{2}{*}{$O^{*}$} & SSN & $43(1.9)$ & $50(4 \cdot 9)$ & $52(2 \cdot 1)$ & $53(3.4)$ & $58(2 \cdot 5)$ & $51(2 \cdot 7)$ \\
\hline & SSE & $46(1 \cdot 2)$ & $47(1.4)$ & $56(3 \cdot 6)$ & $43(2 \cdot 7)$ & $64(3.9)$ & $41(1 \cdot 5)$ \\
\hline
\end{tabular}

a $4 \mathrm{~N}=4$-day-old flies kept on regular food ( 2 days before the start of the adult mortality test).

$6 \mathrm{~N}=6$-day-old flies kept on regular food (at the start of the adult mortality test).

$6 \mathrm{~N}+3 \mathrm{~N}=9$-day-old flies, transferred from regular food to fresh regular food at an age of 6 days (survivors on regular food at the end of the adult mortality test).

$6 \mathrm{~N}+3 \mathrm{E}=9$-day-old flies, transferred from regular food to ethanol supplemented food ( 25 per cent $v / v)$ at an age of 6 days (survivors on ethanol food at the end of the adult mortality test).

$6 \mathrm{~N}+3 \mathrm{~N}+3 \mathrm{~N}=12$-day-old flies; survivors on regular food transferred to regular food for another 3 days at the end of the adult mortality test.

$6 \mathrm{~N}+3 \mathrm{E}+3 \mathrm{~N}=12$-day-old flies; survivors on ethanol food transferred to regular food for another 3 days at the end of the adult mortality test. 


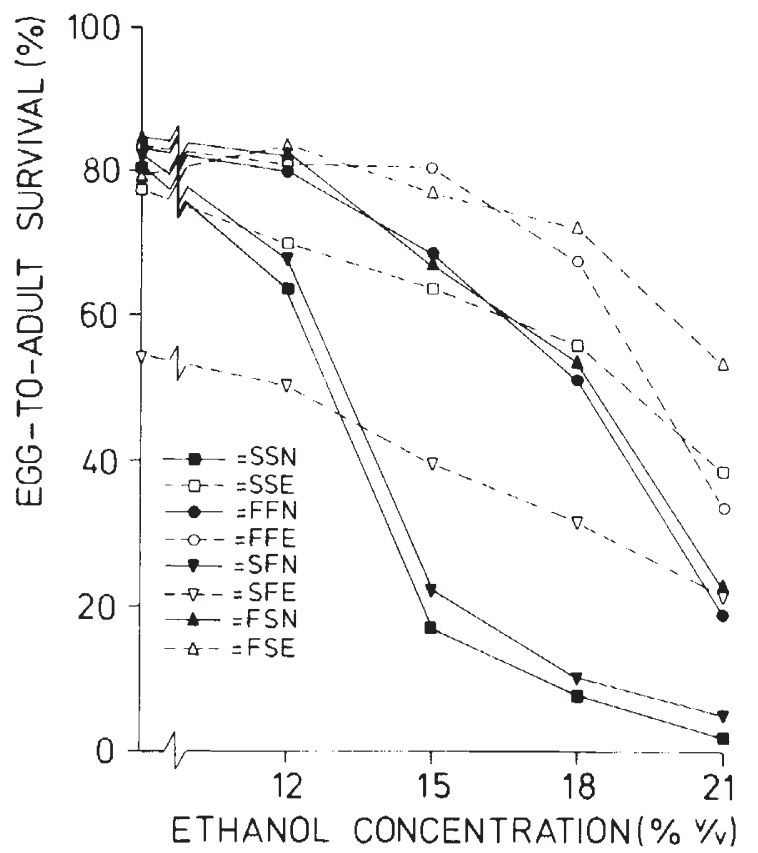

Figure 2 Egg-to-adult survival ( $\delta^{*}$ and $\$ \%$ combined) of several crosses between $A d h$-genotypes in relation to ethanol concentration. The first symbol refers to the $A d h$ genotype of the mother; the second to that of the father. The third symbol refers to the medium on which the strains were kept for about 100 generations.

far greater than the difference between the $\mathrm{E}$ strains.

A probit analysis of egg-to-adult survival was performed to quantify the increase in tolerance to ethanol. The resulting median lethal doses (those concentrations of ethanol that gave rise to an eggto-adult survival of 50 per cent) are given in table 4. The figures in this table again show that, except

Table 4 Median lethal doses $\left(\mathrm{LD}_{50}\right)$ of ethanol, expressed as percentages by volume of ethanol in the food, for egg-toadult survival, 95 per cent confidence intervals are given in parentheses*

\begin{tabular}{|c|c|c|c|}
\hline \multicolumn{2}{|c|}{$N$ strains } & \multicolumn{2}{|c|}{ E strains } \\
\hline FFN & $16 \cdot 8(15 \cdot 7-17 \cdot 9)$ & FFE & $20 \cdot 7(19 \cdot 0-22 \cdot 5)$ \\
\hline FSN & $17 \cdot 3(16 \cdot 2-18 \cdot 5)$ & FSE & $25 \cdot 0(21 \cdot 6-28 \cdot 8)$ \\
\hline SFN & $13 \cdot 1(12 \cdot 4-13 \cdot 9)$ & SFE & $12 \cdot 0(10 \cdot 3-13 \cdot 8)$ \\
\hline SSN & $12 \cdot 6(11 \cdot 9-13 \cdot 3)$ & SSE & $18 \cdot 4(16 \cdot 1-20 \cdot 8)$ \\
\hline
\end{tabular}

* As no significant differences between males and females were observed the sexes were lumped.

for SFE and SSE, the viabilities of eggs laid by mothers of the same strain did hardly differ. With regard to the $\mathrm{N}$ strains, however, there were differences in $\mathrm{LD}_{50}$ between the genotypes with $\mathrm{SS}$ and
FF mothers. The same was found for the E strains except that the differences were less marked and not significant in all cases. Comparison of $\mathbf{N}$ and E of the same $A d h$ genotype did reveal that generally the $L_{50}$ 's of the former group were significantly lower than those of the latter group. Again SFE formed an exception. Obviously the E strains had been adapted during the long period of exposure to ethanol.

For all ethanol concentrations the total viability was corrected for the viability on regular food and a three way analysis of variance (after angular transformation) was performed. The results are given in table 5. It is clear, that irrespective of the ethanol concentration there was a significant effect of the Adh genotypes. Significant differences between genotypes were tested by Tukey's test for multiple comparisons ( $\mathrm{Li}, 1964)$. The results are shown in the bottom part of the table. Again the influence of the maternal effect in the $\mathrm{N}$ strains was obvious: FFN and FSN were much more viable than $\mathrm{SSN}$ and SFN.

On 12 per cent ethanol there was no significant effect of the selection regime yet. This amount of ethanol did not cause sufficiently high mortalities in the juvenile life stages. On higher concentrations of ethanol a significant effect of the selection regimes was always observed; the $\mathrm{E}$ strains survived far better than the $\mathrm{N}$ strains. Furthermore the maternal effect also appeared to be important in the E strains: the viability of eggs from FFE mothers was higher than the viability of eggs from SSE mothers. The significant interaction between $A d h$ genotypes and selection regimes (table 5) can probably be explained by the relatively large difference in survival between eggs from SSN and SSE females compared with the much smaller difference between eggs from FFN and FFE females: the ratio $(\mathrm{SSE}+\mathrm{SFE}) /(\mathrm{SSN}+\mathrm{SFN})$ was far greater than the ratio $(\mathrm{FFE}+\mathrm{FSE}) /(\mathrm{FFN}+\mathrm{FSN})$.

\section{(iv) The relation between egg-to-adult survival and developmental time}

A probit-analysis using the fraction of adults emerged at different times and expressed as a fraction of total emergence was performed to determine the median developmental times $\left(\mathrm{DT}_{50}\right)$ of the Adh genotypes.

As there were no significant differences between the sexes, except for regular food where females developed faster than males, $\mathrm{DT}_{50}$ 's were calculated for the total number of adults ( $\delta$ and $q$ combined) at each time. The results are given in table 6. The data in this table show that SSN, FFN 
Table 5 Analysis of variance of egg-to-adult survival. In the bottom part the genotypes are ranked for each ethanol concentration in decreasing order for ethanol tolerance ( $\delta \sigma^{\circ}$ and $q+q$ combined because there was no significant effect of the sexes). Genotypes that are not significantly different at the 5 per cent level (Tukey's-test for multiple comparisons) are underlined by a common line

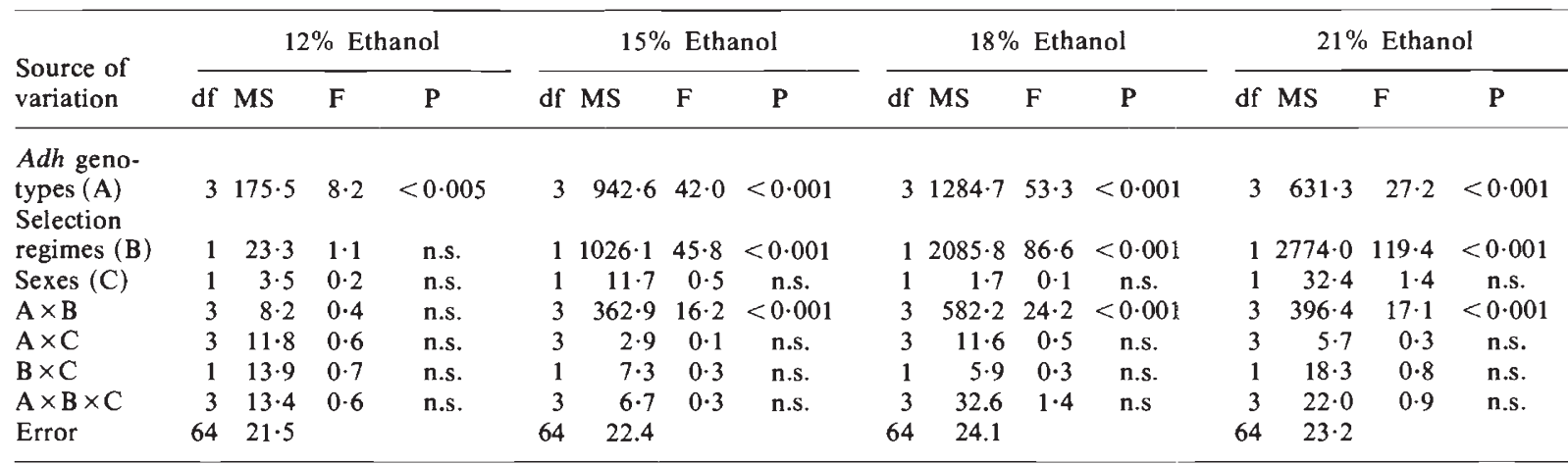

n.s. $=$ not significant at the 5 per cent level.

\begin{tabular}{|c|c|c|c|c|c|c|c|c|}
\hline $12 \%$ Ethanol & FSE & FFE & FSN & FFN & SFE & SSE & SFN & SSN \\
\hline $15 \%$ Ethanol & FFE & FSE & FFN & SSE & $\overline{\text { FSN }}$ & SFE & SFN & SSN \\
\hline $18 \%$ Ethanol & FSE & FFE & SSE & FSN & FFN & SFE & SFN & SSN \\
\hline $21 \%$ Ethanol & FSE & SSE & FFE & SFE & FSN & FFN & SFN & SSN \\
\hline
\end{tabular}

and FSN developed significantly faster compared with the corresponding E strains except for 21 per cent ethanol. At the latter ethanol concentration, however, relatively large standard errors were found. FF developed faster than SS; there was a tendency of a still faster development of the heterozygotes, especially at the higher ethanol concentrations. Although a test for ranking correlation (Sokal and Rohlf, 1981) between developmental time and egg-to-adult survival was not significant there was a tendency for a longer development in the better survivors. Generally the E strains had a somewhat longer $\mathrm{DT}_{50}$ than the $\mathrm{N}$ strains, but again SFE was an exception as it developed faster than the corresponding SFN.

\section{(v) The relation between egg-to-adult survival and $A D H$ activity}

A survey of the in vitro ADH activities in several juvenile life stages is given in table 7 .

In early eggs in vitro ADH activities of corresponding identical $A d h$ genotypes were more or less equal on regular food and on food supplemented with 15 per cent ethanol. In late eggs, however, the situation was changed. Generally $\mathrm{ADH}$ activities on regular food showed a decrease compared with early eggs (especially for the $\mathrm{N}$ types), while ADH activities on 15 per cent ethanol showed a slight but not significant increase. During larval development ADH activity increased rapidly; the percentage increase for the $E$ genotypes was significantly higher than for the corresponding $\mathrm{N}$ genotypes: the mean ratio L I/Eggs II was about $7 \cdot 6$ for SSE, FFE and FSE, 13.8 for SFE, 4.6 for SSN, FFN and FSN and about $11 \cdot 3$ for SFN. Furthermore the absolute increase in activity on food supplemented with ethanol always exceeded the absolute increase on regular food when the same life stages were compared.

The deciding influence of the genotype of the mothers on $\mathrm{ADH}$ activities during the early juvenile life stages is worth particular note. Initially ADH activities of eggs and larvae of the reciprocal heterozygotes differed very strongly. It is clear that activity of eggs laid by mothers of the same $A d h$ genotype was independent of whether they were on normal or on ethanol containing food. The influence of this very strong maternal effect was even perceptible at the late first instar (see for instance the differences between FSN and FSE compared with SFN and SFE respectively). During the pupal stage ADH activities of all genotypes decreased very strongly (30-50 per cent). 
Table 6 Median developmental times $\left(\mathrm{DT}_{50}\right)$ of egg-to-adult survival expressed in hours together with their 95 per cent confidence intervals (given in parentheses). The bottom part of the table shows the types in decreasing order of developmental time for each ethanol concentration. Types not significantly different at the 5 per cent level (Tukey's test for multiple comparisons) are underlined by a common line

\begin{tabular}{llll}
\hline Strain & Regular food & $12 \%$ Ethanol & $15 \%$ Ethanol \\
\hline FFN & $299 \cdot 3(297 \cdot 7-301 \cdot 4)$ & $399 \cdot 4(395 \cdot 3-403 \cdot 5)$ & $457 \cdot 9(453 \cdot 4-462 \cdot 5)$ \\
FSN & $306 \cdot 6(304 \cdot 8-308 \cdot 5)$ & $404 \cdot 8(400 \cdot 9-408 \cdot 8)$ & $449 \cdot 9(446 \cdot 3-453 \cdot 6)$ \\
SFN & $305 \cdot 2(303 \cdot 0-307 \cdot 4)$ & $404 \cdot 1(401 \cdot 3-407 \cdot 0)$ & $446 \cdot 6(441 \cdot 7-451 \cdot 5)$ \\
SSN & $308 \cdot 5(305 \cdot 1-311 \cdot 0)$ & $434 \cdot 5(431 \cdot 2-437 \cdot 8)$ & $482 \cdot 7(477 \cdot 5-488 \cdot 0)$ \\
FFE & $315 \cdot 4(313 \cdot 7-317 \cdot 1)$ & $428 \cdot 0(424 \cdot 5-431 \cdot 5)$ & $472 \cdot 9(467 \cdot 7-478 \cdot 3)$ \\
FSE & $313 \cdot 0(310 \cdot 8-315 \cdot 2)$ & $411 \cdot 5(409 \cdot 0-414 \cdot 1)$ & $461 \cdot 0(456 \cdot 4-465 \cdot 8)$ \\
SFE & $297 \cdot 6(295 \cdot 5-299 \cdot 9)$ & $396 \cdot 4(393 \cdot 5-399 \cdot 4)$ & $440 \cdot 5(435 \cdot 9-445 \cdot 1)$ \\
SSE & $316 \cdot 9(314 \cdot 5-319 \cdot 4)$ & $441 \cdot 8(438 \cdot 3-445 \cdot 3)$ & $495 \cdot 1(489 \cdot 7-500 \cdot 6)$ \\
\hline
\end{tabular}

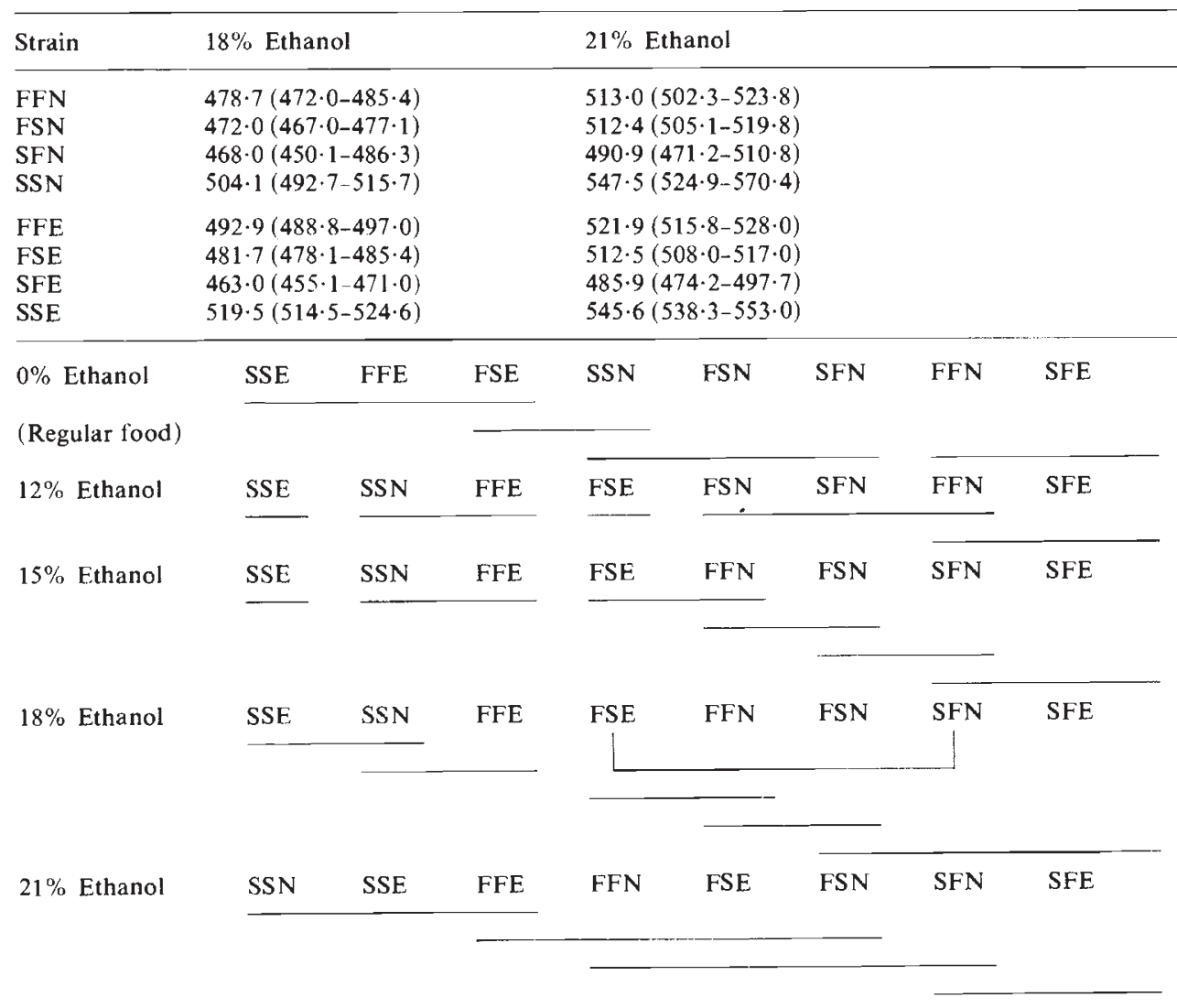

\section{DISCUSSION}

Considerable genotypic differences in survival on ethanol supplemented food have been observed in this study, both in the adult and in the juvenile life stages. FF flies survive better than SS flies due to differences in ADH activity. This result is in agreement with earlier findings of Briscoe et al. (1975), Morgan (1975), Oakeshott (1976) and van Delden and Kamping (1980). Oakeshott et al. (1980), however, also reported, that after exposure for 45 minutes to ethanol fumes SS flies survived better than FF flies. Later experiments of Ziolo and Parsons (1982) showed the same results. This phenomenon may be connected with the finding that ethanol vapours can be taken up by the respiratory system and may subsequently be used as food (van Herrewege and David, 1978). This is clearly quite a different situation physiologically from that of exposure to ethanol containing food, since in the latter case energy can be obtained from sources other than ethanol. Longterm exposure to ethanol food gives an increase in adult tolerance to ethanol for both Adh genotypes. The relative 
Table 7 Mean ADH activities in five juvenile life stages, expressed as $\Delta \mathrm{E} \min ^{-1} \cdot \mathrm{mg} \mathrm{protein}^{-1}$; standard errors are given in parentheses. Individuals were kept on regular $(\mathrm{N})$ or ethanol supplemented food $(\mathrm{E})^{*}$

\begin{tabular}{|c|c|c|c|c|c|c|}
\hline \multicolumn{7}{|c|}{ Life stage $\dagger$} \\
\hline Strain & Food & Eggs 1 & Eggs II & L I & L III & $\mathbf{P}$ \\
\hline SSN & $\begin{array}{l}\mathrm{N} \\
\mathrm{E}\end{array}$ & $\begin{array}{l}48 \cdot 7(3 \cdot 0) \\
44 \cdot 2(6 \cdot 5)\end{array}$ & $\begin{array}{l}26 \cdot 7(0.9) \\
48.4(4 \cdot 2)\end{array}$ & $\begin{array}{l}132.4(11.0) \\
217 \cdot 7(13 \cdot 7)\end{array}$ & $\begin{array}{l}294 \cdot 1(8 \cdot 2) \\
378 \cdot 9(22 \cdot 2)\end{array}$ & $\begin{array}{l}216.3(16.5) \\
285.4(15.9)\end{array}$ \\
\hline SSE & $\begin{array}{l}\mathrm{N} \\
\mathrm{E}\end{array}$ & $\begin{array}{l}43 \cdot 1(4 \cdot 4) \\
49 \cdot 1(6 \cdot 2)\end{array}$ & $\begin{array}{l}29 \cdot 1(2 \cdot 6) \\
54 \cdot 0(2 \cdot 5)\end{array}$ & $\begin{array}{l}269 \cdot 6(8 \cdot 1) \\
469 \cdot 2(30 \cdot 9)\end{array}$ & $\begin{array}{l}431 \cdot 8(12 \cdot 5) \\
710 \cdot 4(27 \cdot 7)\end{array}$ & $\begin{array}{l}270 \cdot 9(12 \cdot 2) \\
347 \cdot 6(25 \cdot 1)\end{array}$ \\
\hline FFN & $\begin{array}{l}\mathrm{N} \\
\mathrm{E}\end{array}$ & $\begin{array}{l}147 \cdot 7(4 \cdot 3) \\
145 \cdot 6(15 \cdot 4)\end{array}$ & $\begin{array}{l}109 \cdot 5(5 \cdot 8) \\
154 \cdot 8(12 \cdot 3)\end{array}$ & $\begin{array}{l}525.9(33.5) \\
716.6(10.0)\end{array}$ & $\begin{array}{l}1038 \cdot 2(24 \cdot 0) \\
1856 \cdot 6(26 \cdot 4)\end{array}$ & $\begin{array}{l}564 \cdot 7(22 \cdot 6) \\
983 \cdot 0(36 \cdot 2)\end{array}$ \\
\hline FFE & $\begin{array}{l}\mathrm{N} \\
\mathrm{E}\end{array}$ & $\begin{array}{l}139 \cdot 7(2 \cdot 1) \\
144 \cdot 0(11 \cdot 3)\end{array}$ & $\begin{array}{l}115 \cdot 3(8 \cdot 2) \\
154 \cdot 6(13 \cdot 6)\end{array}$ & $\begin{array}{r}911 \cdot 6(57 \cdot 9) \\
1116 \cdot 2(14 \cdot 2)\end{array}$ & $\begin{array}{l}1611 \cdot 6(30 \cdot 0) \\
2247 \cdot 7(32 \cdot 5)\end{array}$ & $\begin{array}{l}752 \cdot 5(22 \cdot 6) \\
988 \cdot 2(35 \cdot 2)\end{array}$ \\
\hline SFN & $\begin{array}{l}\mathrm{N} \\
\mathrm{E}\end{array}$ & $\begin{array}{l}42 \cdot 6(4 \cdot 0) \\
47 \cdot 4(3 \cdot 9)\end{array}$ & $\begin{array}{l}34 \cdot 2(3 \cdot 5) \\
52 \cdot 7(6 \cdot 8)\end{array}$ & $\begin{array}{l}413 \cdot 4(17 \cdot 3) \\
551 \cdot 1(39 \cdot 5)\end{array}$ & $\begin{array}{r}810 \cdot 0(25 \cdot 0) \\
1108 \cdot 2(30 \cdot 8)\end{array}$ & $\begin{array}{l}421 \cdot 0(21 \cdot 9) \\
689 \cdot 5(32 \cdot 6)\end{array}$ \\
\hline SFE & $\begin{array}{l}\mathrm{N} \\
\mathrm{E}\end{array}$ & $\begin{array}{l}45 \cdot 9(3 \cdot 3) \\
43.9(6 \cdot 7)\end{array}$ & $\begin{array}{l}37 \cdot 8(2 \cdot 5) \\
49 \cdot 9(1 \cdot 1)\end{array}$ & $\begin{array}{l}496 \cdot 6(13 \cdot 3) \\
725 \cdot 2(22 \cdot 5)\end{array}$ & $\begin{array}{r}949 \cdot 2(37 \cdot 3) \\
1202 \cdot 1(21 \cdot 2)\end{array}$ & $\begin{array}{l}436 \cdot 0(20 \cdot 5) \\
709 \cdot 1(20 \cdot 2)\end{array}$ \\
\hline FSN & $\begin{array}{l}\mathrm{N} \\
\mathrm{E}\end{array}$ & $\begin{array}{l}142 \cdot 1(11 \cdot 1) \\
148 \cdot 3(9 \cdot 6)\end{array}$ & $\begin{array}{l}107 \cdot 6(7 \cdot 0) \\
152 \cdot 1(9 \cdot 0)\end{array}$ & $\begin{array}{l}478 \cdot 3(38 \cdot 3) \\
681 \cdot 0(22 \cdot 8)\end{array}$ & $\begin{array}{r}842 \cdot 6(20 \cdot 2) \\
1119 \cdot 5(13 \cdot 6)\end{array}$ & $\begin{array}{l}438.0(10.8) \\
591.9(29.1)\end{array}$ \\
\hline FSE & $\begin{array}{l}\mathrm{N} \\
\mathrm{E}\end{array}$ & $\begin{array}{l}134 \cdot 3(6 \cdot 6) \\
138 \cdot 0(10 \cdot 6)\end{array}$ & $\begin{array}{c}81.5(0.9) \\
143.8(10.5)\end{array}$ & $\begin{array}{l}561 \cdot 6(36 \cdot 7) \\
766.6(22 \cdot 8)\end{array}$ & $\begin{array}{r}923.7(14.5) \\
1248.5(34.8)\end{array}$ & $\begin{array}{l}429.1(9 \cdot 0) \\
584.4(12 \cdot 1)\end{array}$ \\
\hline
\end{tabular}

* The number of replicates was three.

$\dagger$ For abbreviations see materials and methods.

increase in $\mathrm{LD}_{50}$ varies from 5 per cent for the $\mathrm{FFE}$ females to 15 per cent for the SSE females, while males show intermediate increases in survival of about 10 per cent. David and Bocquet (1977), Gibson et al. (1979) and Dorado and Barbancho (1984) have successfully selected for ethanol tolerance; they found a higher survival for flies from selected strains compared with flies from the corresponding control strains. David and Bocquet (1977) even reported a more than twofold increase in $\mathrm{LD}_{50}$.

$\mathrm{ADH}$ activity measurements in adults confirmed the earlier results of a substantially higher in vitro activity of FF flies compared with SS flies (Gibson, 1972; Kamping and van Delden, 1978; Maroni, 1978; van Delden and Kamping, 1980). Despite the fact that in D. melanogaster ADH plays an important role in the detoxification of alcohols (McKenzie and Parsons, 1974; David et al., 1976; 1978; 1981; van Delden et al., 1978) no consistent correlation between in vitro $\mathrm{ADH}$ activity and adult survival on ethanol food could be demonstrated in the present study. On the contrary, ethanol food seemed to arrest the age dependent increase in ADH activity in males of the E strains which had been observed on regular food. For females no differences were observed between in vitro $\mathrm{ADH}$ activities of $\mathrm{N}$ and $\mathrm{E}$ flies. The finding that in vitro ADH activity alone cannot predict adult survival on ethanol containing media is demonstrated by the fact that SSE females and FFN males survived equally well but showed a large difference in $\mathrm{ADH}$ activity.

Furthermore survival of SSE females exceeded survival of males though males possessed higher $\mathrm{ADH}$ activities; for FFE, however, both survival and $\mathrm{ADH}$ activity were higher for males than females. Therefore a consistent relation between in vitro $\mathrm{ADH}$ activity and adult survival after adaptation to ethanol must be denied. These findings contradict those of McDonald et al. (1977), who reported increased $\mathrm{ADH}$ activities and $\mathrm{ADH}$ amounts in a strain selected for increased tolerance to ethanol. In this case, however, the selection procedure was basically different from ours, as selection was only exercised on adults by exposing the flies during three days to an aqueous solution of sucrose supplemented with ethanol.

In the adult experiment $\mathrm{ADH}$ activities were measu red per unit of live weight. Part of the activity measurements were repeated in another experiment. In that case the ADH activity was expressed both per unit of live weight and per unit of protein. The results were nearly identical both qualitatively and quantitatively.

For egg-to-adult survival the situation was found to be completely different. Because the juvenile life stage is probably the most important phase of selection, heterozygotes were also tested in this case. A complication was that the viability 
of SFE eggs appeared to be less than viabilities of all other genotypes. The lower survival of SFE was highly reproducible and from a series of tests it appeared that only 69 per cent of the eggs hatched on regular food and gave rise to first instar larvae, compared with a hatch of 92 per cent for the other genotypes. Once the first larval instar was reached, the viability of SFE was normal. Hence it must be concluded, that the lower survival of SFE is caused by unknown factors operating only during the eggstage.

As in the adult also in the juvenile life stage selection resulted in an increased tolerance to ethanol. Fig. 2 shows that egg-to-adult survival of the selected flies (with the exception of SFE) exceeded survival of the control flies. When expressed as median lethal doses $\left(\mathrm{LD}_{50}\right)$, increases in tolerance to ethanol varied from about $25 \mathrm{per}$ cent (FF) up to about 50 per cent (SS). Dorado and Barbancho (1984) also reported higher survival of selected strains compared to control strains on food supplemented with ethanol, especially in case of SS strains. Experiments of van Delden and Kamping (1983) gave the same results for strains exposed to hexanol food. After 90 generations of exposure to hexanol egg-to-adult survival of the selected $(\mathrm{H})$ strains was far higher than survival of the control (N) strains. In this case, however, the increase in $\mathrm{LD}_{50}$ of hexanol for FF exceeded the increase for SS. The larger increase in tolerance to ethanol of SSE compared with FFE may be due to the higher intensity of selection in SSE compared with FFE due to lower ADH activity of SSE. The better survival of FSE and, to a lesser extent, FSN compared with FFE and FFN respectively (see $\mathrm{LD}_{50}$ 's in table 4) may indicate the occurrence of heterosis. However, due to the low hatchability of SFE and the important influence of the maternal effect on egg-to-adult survival of SFN (see later) clearcut conclusions concerning the occurrence of heterosis cannot be drawn.

The resemblance in fig. 2 between the survival curves of SSN and SFN and those of FFN and FSN is striking. The difference in survival between the two pairs of genotypes increased with increasing ethanol concentrations; the ratio between survival of SFN and FSN decreased from 0.97 for regular food via $0.83,0.34$ and 0.19 to $0 \cdot 17$ for 21 per cent ethanol food.

Apparently the $A d h$ genotype of the mother is of paramount importance for egg-to-adult survival. The egg cytoplasm of embryos contains proteins and mRNAs from the mother (Gerasimova and Smirnova, 1979). It is known (Wright and Shaw, 1974; Leibenguth et al., 1979) that in eggs of $D$. melanogaster the production of their own $\mathrm{ADH}$ does not start until the 18th hour, so until that time only the $\mathrm{ADH}$ or mRNA (for manufacturing $\mathrm{ADH}$ ) from the mother is present. As the activity of F-ADH exceeds the activity of S-ADH this explains the difference in egg-to-adult survival mentioned above. In contrast to the situation in the adult life stage significant differences in in vitro $\mathrm{ADH}$ activity are detected between corresponding genotypes during the pre-adult life stage. In early eggs (mean age 2 hours) this is not yet the case, neither on regular food nor on ethanol food. Apparently the amount of $\mathrm{ADH}$ included in the egg-cytoplasm by the mothers (Kerver, in preparation) is equal for $\mathrm{N}$ and $\mathrm{E}$ strains. Late eggs, however, differ considerably in $\mathrm{ADH}$ activity depending on the food they are laid on. Compared with early eggs, ADH activities of late eggs from regular food are decreased, a finding which was also observed by Leibenguth et al. (1979).

On ethanol food, however, ADH activities stay constant. This causes significant differences between ADH activities of eggs laid on regular food and eggs laid on ethanol food in favour of the latter. This result is in agreement with earlier findings of Bijlsma-Meeles (1979) who reported that ADH activity in 18 hour old ethanol-treated eggs was significantly higher than $\mathrm{ADH}$ activity in non-treated eggs. An explanation for the differences between the in vitro ADH activities of late eggs from regular food and ethanol containing food found in this study may be that in the latter case an enzyme-substrate complex can be formed. It is well documented that such a complex is generally more stable than the free enzyme (Katunuma et al., 1971 $a, b$; Litwack and Rosenfield, 1973). If such a phenomenon occurs here this may explain the constancy of ADH activity on ethanol food and the decrease in activity on regular food.

The far reaching influence of the maternal effect is striking; even in late first instar larvae there was still a significant difference between ADH activities of reciprocal heterozygotes. Furthermore a larger absolute increase with time was found on ethanol food than on regular food. The latter finding may be explained by induction of enzyme activity in the presence of the relevant substrate, ethanol. Interestingly Horikawa et al. (1967) found that addition of ethanol $(2.5$ per cent $\mathrm{v} / \mathrm{v})$ to a suspension of embryonic cells of $D$. melanogaster stimulated $\mathrm{ADH}$ activity. If the maternal effect is also somehow related to the rate of induction of larval $\mathrm{ADH}$ then this may explain its far reaching influence. If the production of $\mathrm{ADH}$ is indeed stimulated by the presence of ethanol, as suggested 
above, this may explain the higher $\mathrm{ADH}$ activities found in the $\mathrm{E}$ strains compared with the $\mathrm{N}$ strains, for the E strains were exposed to ethanol during their whole life cycle.

The decline in ADH activity of the E strains during the pupal period exceeded the decline of the $\mathrm{N}$ strains. This is in good agreement with the results of the activity assays of adults, where no differences were found between $\mathrm{E}$ and $\mathrm{N}$ strains. Apparently ADH activities of the $\mathrm{E}$ and $\mathrm{N}$ strains are reduced to the same level.

A correlation was observed between in vitro ADH activity and egg-to-adult survival in the sense that selected individuals showed higher activities and better survival than the corresponding control individuals (with the exception of SFE on 12 per cent ethanol). Again there was no absolute relation with in vitro ADH activity; the survival of FSE at least equaled the survival of FFE, but $\mathrm{ADH}$ activities of the latter genotype were significantly higher over the total larval period. The same holds for SSN and SFN and for FSN and FFN. On regular food significant differences were observed in developmental time: $\mathrm{SS}>\mathrm{FS}=\mathrm{SF}>\mathrm{FF}$. This is in agreement with earlier results of Oakeshott (1976; 1977), van Delden and Kamping (1979) and Dorado and Barbancho (1984). On ethanol supplemented media, however, heterozygotes tended to develop faster than both homozygotes. Dorado and Barbancho (1984) found that the difference between developmental times of FF and FS individuals decreased, but in their study FF still had the fastest development. Oakeshott (1976; 1977), David and Bocquet (1977) and Dorado and Barbancho (1984) found that long term selection for ethanol tolerance caused shortening of developmental times of the selected strains. Furthermore they reported that this was associated with an increase in egg-to-adult survival. Our results seem to point to the reverse. Although a test for ranking correlation between egg-to-adult survival and developmental time was not significant, it appears that the $\mathrm{N}$ genotypes develop significantly faster compared with the E genotypes both on regular and on ethanol food (for $\mathrm{DT}_{50}$ see table 6), but egg-to-adult survival of the E genotypes significantly exceeds survival of the corresponding $\mathrm{N}$ genotypes (see table 5). Therefore it seems, that the increased survival may be associated with the lengthening of developmental time.

Again SFE forms an exception: compared with SFN its $\mathrm{DT}_{50}$ was shortened; maybe this-genetically fixed-faster development is somehow related to the poor egg-to-adult survival of SFE. The precise cause of the prolonged developmental times of the E strains compared with the $\mathrm{N}$ strains remains unclear. In this respect it is often found in insects, that long term exposure to detrimental substances (including insecticides) causes a genetically determined lengthening of developmental times associated with increased tolerance (Parsons, 1973; Perry and Agosin, 1974).

As the strongest selection will be exercised during pre-adult life it is to be expected that adaptation will mainly be induced during that period. For a further analysis of adaptation therefore the relative resistance of the $\mathrm{E}$ and $\mathrm{N}$ strains for egg-to-adult survival was plotted in fig. 3 . If

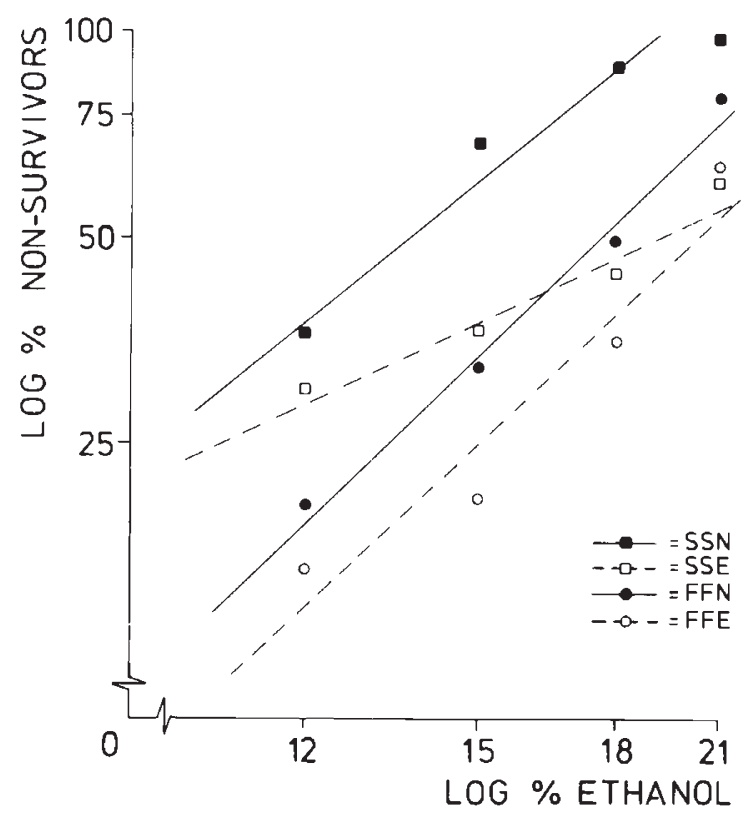

Figure 3 Relative resistance to ethanol of selected (E) and nowselected (N) strains of different $A d h$-genotypes. The E strains were kept on food containing ethanol (18 per cent $\mathrm{v} / \mathrm{v}$ ) for about 90 generations; the $\mathrm{N}$ strains were kept on regular food all the time.

mortality probabilities on ethanol food follow the normal distribution then logarithmic plotting of mortality percentages against ethanol concentrations results in a linear relationship between these two factors. If furthermore mortality chances are identical irrespective of ADH activity then, for two strains derived from the same original population in the same way, but differing in ADH activity, it is to be expected that the regression lines representing the relative resistance to ethanol will be parallel. In this case the position of these regression lines will be determined by the level of $\mathrm{ADH}$ activity. Logarithmic plotting of the percentage of 
non-survivors of FFN and SSN at the ethanol concentrations used indeed shows a linear relationship between mortality and amount of ethanol. Furthermore the regression line of FFN lies below that of SSN, but the regression coefficients are not significantly different $(t=0 \cdot 209 ;$ n.s. $)$. Apparently ADH activity only determines the position, and not the slope of the regression lines. On ethanol food there will be selection for ethanol tolerance and selection at the same ethanol concentration against SS will be more severe than selection against FF. Eventually the strains will adapt to ethanol and this means that the regression lines for relative resistance will be lowered.

If adaptation is obtained through $\mathrm{ADH}$ activity only it is to be expected that the regression lines of the E strains will still parallel those of the $\mathrm{N}$ strains. If, however, adaptation is also brought about by other loci not involved in the production or regulation of $\mathrm{ADH}$, then the slopes of the lines may change. From fig. 3 it is clear that the regression line of FFE lies below that of FFN but is still parallel to it $(t=0 \cdot 118 ;$ n.s. $)$, so in this case adaptation might be mainly associated with the Adh locus. In the case of the SSE strains, however, the regression line is not only lowered compared with SSN, but the slope has also changed $(t=4.9$; $p<0 \cdot 05$ ). Therefore in this case the $A d h$ locus is likely not the only factor involved in adaptation. The SSE and FFE regression lines have an intersection point, suggesting that at ethanol concentrations above that point SSE should survive better than FFE. In our experiments this is in fact found for the highest ethanol concentration tested, 21 per cent $\mathrm{v} / \mathrm{v}$. Our results fortify the suggestion of Dorado and Barbancho (1984) that there are differences in the adaptation mechanisms for $A d h^{F}$ and $A d h^{S}$ strains selected for ethanol tolerance.

Overall it can be concluded that both the SSE and FFE strain have considerably increased their tolerance to ethanol. This is mainly accomplished during juvenile life. The mechanism of the adaptation is not fully elucidated, though it is clear, that $\mathrm{ADH}$ activity, at least during juvenile life, is of great importance. The maternal effect is also of great influence upon the survival of $D$. melanogaster on ethanol containing media. Moreover it is clear that adaptation has not been realised in the same way for SS and FF and that adaptation of SS is relatively better than for FF.

The important role of the $A d h$ locus as an ecologically relevant factor in adaptation to ethanol is confirmed, but it is also clear that other loci play an important role.
Acknowledgements We acknowledge the advice of A. Kamping during the experimental phase of this study and we thank Dr R. Bijlsma for valuable suggestions. Thanks are due to Ms S. Walburgh Schmidt for typing the manuscript and to $\mathrm{H}$. Mulder for preparing the figures.

This investigation was supported by the Foundation for Fundamental Biological Research (BION) which is subsidised by the Netherlands Organisation for the Advancement of Pure Research (Z.W.O.).

\section{REFERENCES}

ANDERSON, D. 1982. Alcohol dehydrogenase activity and ethanol tolerance along the $A d h$ cline in Australia. In: Advances in genetics, development and evolution of Drosophila (S. Lakovaara, ed.) pp. 263-272. Plenum Press, New York.

BIJLSMA-MEELES, E. 1979. Viability in Drosophila melanogaster in relation to age and $\mathrm{ADH}$ activity of eggs transferred to ethanol food. Heredity, 42, 78-89.

BIJLSMA-MEELES, L. ANI VAN DELDEN, w. 1974. Intra- and interpopulation selection concerning the alcohol dehydrogenase locus in Drosophila melanogaster. Nature 247, $369-371$.

BR1SCOE, D. A., ROBERTSON, A. AND MALPICA, M. J. 1975. Dominance at $A d h$ locus in response of adult Drosophila melanogaster to environmental alcohol. Nature, 255, 148149.

CAVENER, D. R. ANI) CLEGG, M. T. 1978. Dynamics of correlated genetic systems. Vl. Multilocus effects of ethanol stress environments. Genetics, 90, 629-644.

CAVENER, D. R. AND CLEGG, M. T. 1981. Multigenic adaptation to ethanol in Drosophila melanogaster. Evolution, 35, 1-10.

CLARKE, B. 1975. The contribution of ecological genetics to evolutionary theory: Detecting the direct effects of natural selection on particular polymorphic loci. Genetics, 79, 101118.

DAVID, J. R. AND BOCQUET, C. 1977. Genetic tolerance to ethanol in Drosophila melanogaster: Increase by selection and analysis of correlated responses. Genetica, 47, 43-48.

DAVID, J. R., BOCQUET, C., ARENS, M. F. AND FOUILlET, P. 1976. Biological role of alcohol dehydrogenase in the tolerance of Drosophila melanogaster to aliphatic alcohols: utilisation of an ADH-null mutant. Biochem. Genet. 14, 989997.

DAVID, J. R., BOCQUET, C., VAN HERREWEGE, J., FOUILLET, P. AND ARENS, M. F. 1978. Alcohol metabolism in Drosophila melanogaster: uselessness of the most active aldehyde oxidase produced by the Aldox locus. Biochem. Genet., 16, 203-211.

DAVID, J. R., VAN HERREWEGE, J., DE SCHEERMAEKERLOUIS, M. AND PLA, E. 1981. Drosophila alcohol dehydrogenase: detoxification of isopropanol and acetone, sub. stances not used in energy metabolism. Heredity, 47, 263268.

DAY, T. H., HII.LIER, P. C. AND ClARKE, B. 1974a. Properties of genetically polymorphic isozymes of alcohol dehydrogenase in Drosophila melanogaster. Biochem. Genet., 11, $141-153$.

I)AY, T. H., HILLIER, P. C. AND CLARKE, B. 1974b. The relative quantities and catalytic activities of enzymes produced by alleles at the alcohol dehydrogenase locus in Drosophila melanogaster. Biochem. Genet., 11, 155-165. 
DORADO, G. AND BARBANCHO, M. 1984. Differential responses in Drosophila melanogaster to environmental ethanol: modification of fitness components at the Adh locus. Heredity, 53, 309-320.

FINNEY, D. J. 1947. Probit analysis. Cambridge University Press, Cambridge.

GERASIMOVA, T. I. AND SMIR NOVA, S. G. 1979. Maternal effect for genes encoding 6-phosphogluconate dehydrogenase and glucose-6-phosphate dehydrogenase in Drosophila melanogaster. Developm. Genet., 1, 97-107.

GIBSON, J. 1970. Enzyme flexibility in Drosophila melanogaster. Nature, 227, 959-960.

GIBSON, J. B. 1972. Differences in the number of molecules produced by two allelic electrophoretic enzyme variants in Drosophila melanogaster. Experientia, 28, 975-976.

GIBSON, J. B., LEWIS, N., ADENA, M. A. AND WILSON, S. R. 1979. Selection for ethanol tolerance in two populations of Drosophila melanogaster segregating alcohol dehydrogenase allozymes. Aust. J. Biol. Sci., 32, 387-398.

HAMRICK, J. L., LINHART, Y. B. AND MITTON, J. B. 1979. Relationships between life history characteristics and electrophoretically detectable genetic variation in plants. Annu. Rev. Ecol. Syst., 10, 173-200.

HICKEY, D. A. AND MCLEAN, M. D. 1980. Selection for ethanol tolerance and $A d h$ allozymes in natural populations of Drosophila melanogaster. Genet. Res., 36, 11-15.

HORIKAWA, M., LING, L. N. L. AND FOX, A. S. 1967. Effects of substrates on gene-controlled enzyme activities in cultured embryonic cells of Drosophila. Genetics, 55, 569-583.

KAMPING, A. AND VAN DELDEN, W. 1978. The alcohol dehydrogenase polymorphism in populations of Drosophila melanogaster. II. Relation between ADH activity and adult mortality. Biochem. Genet., 16, 541-551.

KATANUMA, N., KOMINAMI, E. AND KOMINAMI, S. 1971a. A new enzyme that specifically inactivates apo-protein of pyridoxal enzymes. Biochem. Biophys. Res. Commun., 45, $70-75$.

KATANUMA, N., KITO, K. AND KOMINAMI, E. 1971b. A new protein that specifically inactivates apo-protein of NADdependent dehydrogenases. Biochem. Biophys. Res. Commun., 45, 76-81.

KIMURA, M. 1983. The neutral theory of molecular evolution. Cambridge University Press, Cambridge.

LEIBENGUTH, F., RAMMO, E. AND DUBICZKY, R. 1979. A comparative study of embryonic gene expression in Drosophila and Ephestia. Wilhelm Roux' Arch. Dev. Biol., $187,81-88$.

LEWONTIN, R. C. 1974. The genetic basis of evolutionary change. Columbia University Press, New York.

LI, C. C. 1964. Introduction to experimental statistics. McGrawHill Book Company, New York, London.

LITWACK, G. AND ROSENFIELD, S. 1973. Coenzyme dissociation, a possible determinant of short half-life inducible enzymes in mammalian liver. Biochem. Biophys. Res. Commun., 52, 181- 187.

MARONI, C. 1978. Genetic control of alcohol dehydrogenase levels in Drosophila. Biochem. Genet., 16, 509-523.

MCDONALD, J. F., CHAMBERS, G. K., DAVID, J. AND AYALA, F. J. 1977. Adaptive response due to changes in gene regulation: A study with Drosophila. Proc. Natl. Acad. Sci. USA, $74,4562-4566$

MCKENZIE, J. A. AND MCKECHNIE, S. W. 1978. Ethanol tolerance and the $A d h$ polymorphism in a natural population of Drosophila melanogaster. Nature, 272, 75-76.
MCKENZIE, J. A. AND PARSONS, P. A. 1974. Microdifferentiation in a natural population of Drosophila melanogaster to alcohol in the environment. Genetics, 77, 385-394.

MORGAN, P. 1975. Selection acting directly on an enzyme polymorphism. Heredity, 34, 124-127.

NEVO, E. 1978. Genetic variation in natural populations: Patterns and theory. Theor. Popul. Biol., 13, 121-177.

OAKESHOTT, J. G. 1976. Selection at the alcohol dehydrogenase locus in Drosophila melanogaster imposed by environmental ethanol. Genet. Res., 26, 265-274.

OAKESHOTT, J. G. 1977. Variation in the direction of selection applied by pentanol to the alcohol dehydrogenase locus in Drosophila melanogaster. Aust. J. Biol. Sci., 30, 259-267.

OAKESHOTT, J. G. 1979. Selection affecting enzyme polymorphisms in laboratory populations of Drosophila melanogaster. Oecologia, 143, 341-354.

OAKESHOTT, J. G., GIBSON, J. B., ANDERSON, P. R. AND CHAMP, A. 1980. Opposing modes of selection on the alcohol dehydrogenase locus in Drosophila melanogaster. Aust. J. Biol. Sci., 33, 105-114.

PARSONS, P. A. 1973. Genetics of resistance to environmental stresses in Drosophila populations. Ann. Rev. Genetics, 7, 239-265.

PERRY, A. S. AND AGOSIN, M. 1974. The physiology of insecticide resistance by insects. In: The physiology of insecta vol $I V$, (Rockstein, M., ed.) Academic Press, New York.

POWELL, J. R. 1975. Protein variation in natural populations of animals. Evol. Biol., 8, 79-119.

SOKAL, R. R. AND ROHLF, F. J. 1981. Biometry. W. H. Freeman and Company, San Francisco. pp. 446-447 and 601-609.

THOMPSON, J. N. AND KAISER, T. N. 1977. Selection acting upon slow-migrating $A d h$ alleles differing in enzyme activity. Heredity, 38, 191-195.

VAN DELDEN, w. 1982. The alcohol dehydrogenase polymorphism in Drosophila melanogaster. Selection at an enzyme locus. Evol. Biol., 15, 187-222.

VAN DELDEN, W., BOEREMA, A. C. AND KAMPING, A. 1978. The alcohol dehydrogenase polymorphism in populations of Drosophila melanogaster. I. Selection in different environments. Genetics, 90, 161-191.

VAN DELDEN, W. AND KAMPING, A. 1979. The alcohol dehydrogenase polymorphism in populations of Drosophila melanogaster. III. Differences in developmental times. Genet. Res., 33, 15-27.

VAN DELDEN, W. AND KAMPING A. 1980. The alcohol dehydrogenase polymorphism of Drosophila melanogaster. IV. Survival at high temperature. Genetica, 51, 179-185.

VAN DELDEN, W. AND KAMPING, A. 1983. Adaptation to alcohols in relation to the alcohol dehydrogenase locus in Drosophila melanogaster. Entomol. Exp. Appl., 33, 97-102.

VAN DELDEN, W., KAMPING, A. AND VAN DIJK, H. 1975. Selection at the alcohol dehydrogenase locus in Drosophila melanogaster. Experientia, 31, 418-419.

VAN HERREWEGE, J. AND DAVID, J. R. 1978. Feeding an insect through its respiration: Assimilation of alcohol vapors by Drosophila melanogaster adults. Experientia, 34, 163-164.

WRIGHT, D. A. AND SHAW, C. R. 1970. Time of expression of genes controlling specific enzymes in Drosophila embryos. Biochem. Genet., 4, 385-394.

ZIOLO, L. K. AND PARSONS, P. A. 1982. Ethanol tolerance, alcohol dehydrogenase activity and $A d h$ allozymes in Drosophila melanogaster. Genetica, 57, 231-237. 